ا.د. إيثار عبد الكريم غزال

كلية التربية البينية وعلوم الرياضة / جامعة الموصل

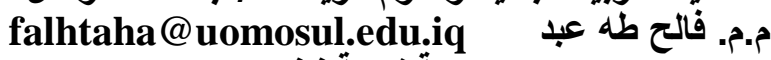
مديرية تربية نينوى

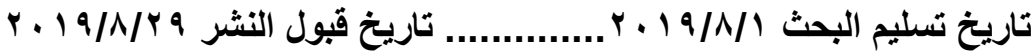

\title{
|ll|
}

يهدف البحث الى بناء اختبارات للقدرات التوافقية للاعبي كرة القدم لأعمار (سا-10) سنة وايجاد الدرجات المعيارية, لها حيث تم استخدام المنهج الوصفي بالأسلوب المسحي لتحقيق هدفي البحث وتكون مجتمع البحث من لاعبي كرة القدم لأعمار سا-10 سنة من اكاديميات كرة القدم في مدينة الموصل, اما عينة البحث فقد ضمت (ع • () لاعبين من اكاديمية نادي الموصل الرياضي واكاديمية الاندلس وتم اختيارهم بطريقة عمدية واستخدم الباحثان تحليل المصادر والبحوث و الاستبيان لتحديد القدرات التوافقية وتم تصميم مجموعة من المواقف السلوكية كاختبارات مقترحة. وتم اجراء تجارب استطلاعية عدة من أجل التعرف على صلاحية الاختبارات, وكان الهدف منها تحديد الأسس العلمية للاختبارات ,وكان من اهم النتائج التي تم التوصل اليها أن الاختبارات المقترحة تتمتع بمعاملات علمية من الصدق والثبات والموضوعية والملائمة مما يدل على أن تصميم الاختبارات قد تم على وفق الطرائق العلمية السليمة للبناء وتم ايجاد الدرجات المعيارية للاختبارات النهائية. الكلمات المفتاحية: (بناء اختبار ، القدرات التوافقية، كرة قدم)

\section{Structure Compatibility Tests for Football Players (Ages 13-15)}

\section{Prof. Dr. Ethar Abdel Karim Ghazal master_20079@yahoo.com} Asst. Lect. . Faleh Taha

falhtaha@uomosul.edu.iq

\section{$\underline{\text { Abstract }}$}

The aim of the research is to structure tests for the compatibility abilities of football players for ages (13-15) years and to find their standard grades. The descriptive method was used in the survey method to achieve the research goals. The research community is one of the football players of 13-15 years of football academies in Mosul. The study sample included 104 players from the Mosul Sports Club Academy and the Andalus Academy. They were selected in a deliberate manner. The researchers used the analysis of sources, research and questionnaire to determine the compatibility abilities. A set of behavioral attitudes were designed as proposed tests. A number of experiments were conducted to determine the validity of the tests. The aim was to determine the scientific basis for the tests. The most important results were that the proposed tests enjoy scientific transactions of honesty, consistency, objectivity and suitability, indicating that 


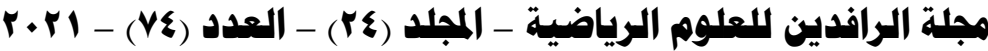

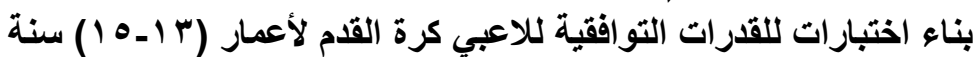

the design of the tests was done in accordance with sound scientific methods of construction Standard scores for final tests were found.

Keywords: (Structure, Compatibility, Football)

$$
\begin{aligned}
& 1 \text { - التعريف بالبحث : } \\
& 1 \text { - } 1 \text { مقدمة البحث وإهميته }
\end{aligned}
$$

تعد لعبة كرة القدم من الأنشطة الرياضية التي تتطلب جانباً كبيراً من اللياقة البدنية والمهارة

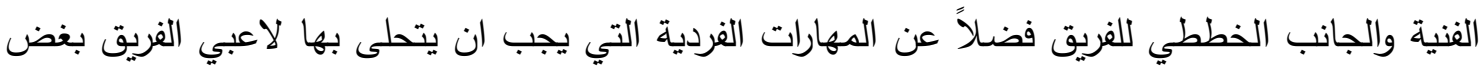
النظر عن مراكز اللعب التي يلعبون فيها ومما لاشك فيه ان الوصول للانجاز الرياضي العالي يتطلب الكثير من المتطلبات ومن هذه المتطلبات القدرات التوافقية، حيث تعمل بثكل متكامل, ومركب مع الصفات البدنية والحركية، والأجهزة الوظيفية للجسم لاعطاء المهارة الرياضية الجمالية والتتاغم، فضلاً عن لهن

تحقيق الهدف منها .

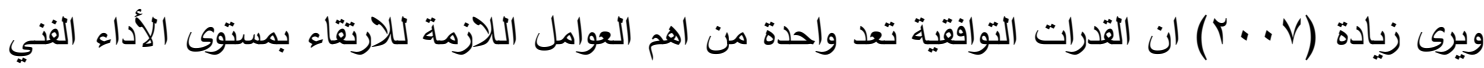
للاعبين, لذلك فإن تتميتها وتطويرها يخدم الجانب الفني والتكتيك بشكل كبير كما ان القدرات التوافقية تعد احد وسائل الضبط والتحكم في الاداءات الحركية المختلفة ، ومن ثم فأن توافر هذه القدرات لدى اللاعبين يمكنهم من الوصول الى افضل درجات توافق الأداء المطلوب لإنجاز أي أداء حركي. ( زيادة : V.... Y،

وتعد القدرات التوافقية بمثابة الأساس لنجاح عمليات التعلم وتحسين الأداء, وفي هذا الصدد

يذكر السيد (1 (. r) ان توافر مستوى جيد من القدرات التوافقية لدى اللاعب يؤدي الى اختزال الزمن اللازم لتعلم واكتساب المهارات الحركية وبالتالي يتم أداء هذه المهارات بشكل اقتصادي في الطاقة المبذولة, كما ان المستوى التوافقي يُمكن اللاعب من تنوع الأداء المهاري في مختلف الأنشطة الرياضية

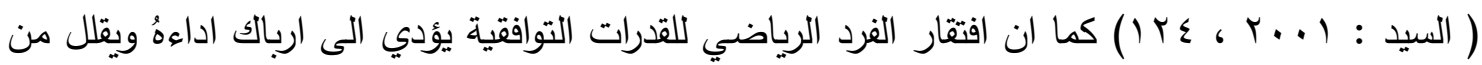

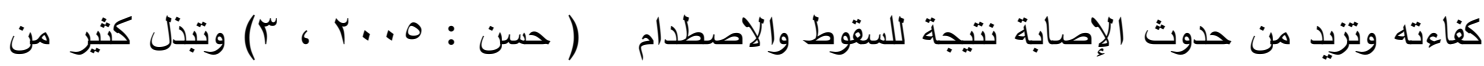
الدول المتقدمة في كرة القدم جهوداً مستمرة لأعداد ناشئي كرة القدم على أسس علمية واضحة بوصفها القاعدة العريضة التي تعتمد عليها لنمو وازدهار اللعبة . مما تقدم تتجلى أهمية البحث الى التعرف على القدرات التوافقية ووضع مجموعة اختبارات لقياسها ولاعتمادها مستقبلاً في تصنيف وانتقاء لاعبي كرة القدم لأعمار (سار-10) سنة, فضلا عن اهمية استخدام الاختبارات كمقياس لمعرفة مستويات الناشئين رومدى تقدمه والاستفادة من محددات الانتقاء لاختيار ناشئي كرة القدم.

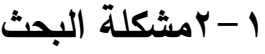

تعد لعبة كرة القدم من الألعاب التي تتصف بالحركة والتغير المستمر والسريع في الأداء الحركي الهجومي والدفاعي ، إذ تعد من الألعاب التنافسية ذات المواقف المتغيرة التي تتطلب قدرات توافقية عالية حتى لتى بلى يستطيع ممارسيها من أداء مهارتها المختلفة. 
ومن خلال إطلاع الباحثان على المراجع والأبحاث التي أجريت في لعبة كرة القدم , تبين ان معظم الأبحاث أجريت كبرامج تدريبية للقدرات التوافقية, وقلة وجود وسيلة لقياس هذه القدرات وبخاصة للناشئين، مما دفع الباحثان الى بناء مجموعة اختبارات لقياس القدرات التوافقية للاعبي كرة القدم وتكمن مشكلة

$$
\text { البحث في الإجابة عن التساؤلات الأتية : }
$$

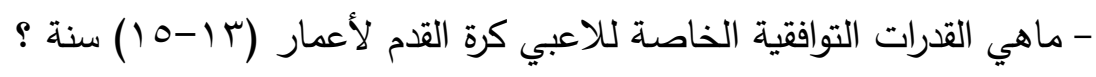
- ماهي الاختبارات الخاصة لقياس القدرات التوافقية ومدى صلاحيتها لعينة البحث ؟

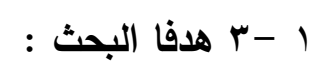

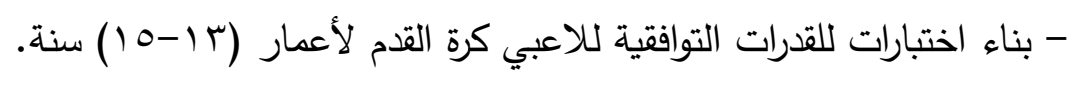
- ايجاد الدرجات المعيارية لاختبارات القدرات التوافقية لعينة البحث

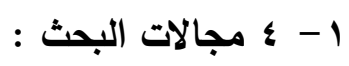

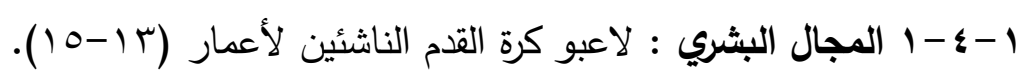

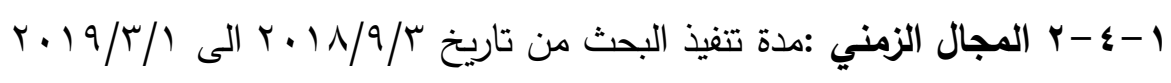
1- - - ب المجال المكاني : الملاعب الرياضية قيد الدراسة للمراكز التدريبية . 1-ه تحديد المصطلحات : القدرة التوافقية وتعرف ايضاً بأنها شروط نفسية حركية عامة للإنجاز

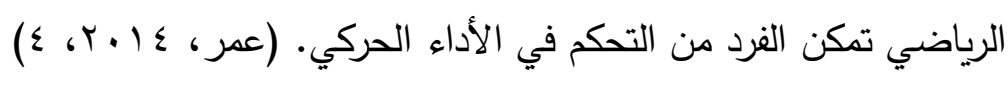

$$
\begin{aligned}
& \text { r - الدراسات السابقة ذات العلاقة }
\end{aligned}
$$

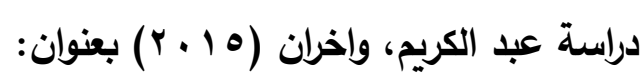

(تصميم اختبار مهاري لقياس الأداء المهاري المركب عند ناشئي كرة القدم)

تهدف هذه الدراسة إلى تصميم اختبار مركب لقياس الأداء المهاري عند الناشئين في أندية كرة القدم

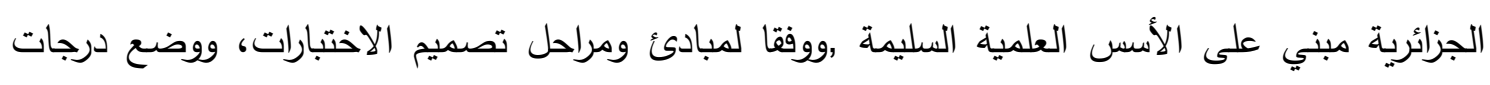
معيارية للاختبار المهاري المركب, والاعتماد عليها في معرفة مستوى الناشئين في أندية كرة القدم الجزائرية، حيث تمثلت عينة البحث في ناشئي كرة القدم الناشئين ضمن الأندية الجزائرية المحترفة

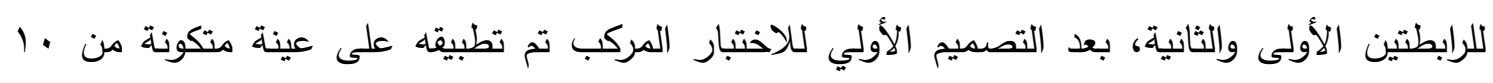
لاعبين من أجل التعرف على صلاحيته من حيث ضمن الاندية الجزائرية المحترفة روبعد التصميم الاولي للاختبار المركب تم تطبيقه على عينة متكونة من (· () لاعبين من اجل التعرف على صلاحيته من حيث التطبيق في تجربة استطلاعية أولى ,حيث تم إدخال بعض التعديلات المقترحة من قبل المتخصين

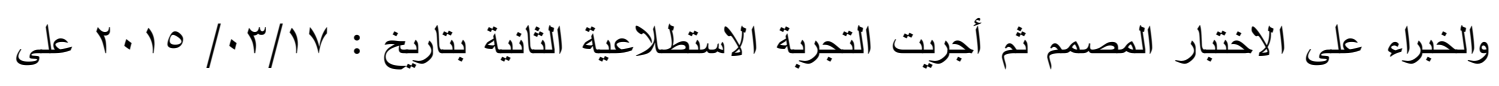

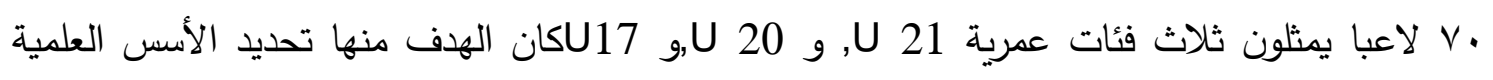
للاختبار , وقد تم الخروج بمجموعة من النتائج كان أهمها أن الاختبار المهاري المصدم يتمتع بدرجات عالية من الصدق والثبات مما يدل على أن تصميم الاختبار تم على وفق الطرائق العلمية السليمة. 
r- إجراءات البحث

r-

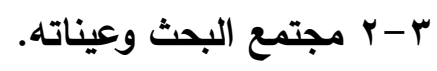

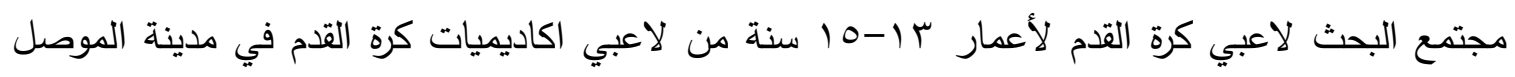

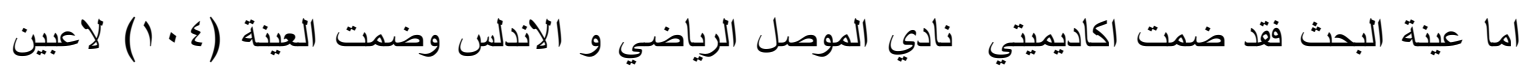

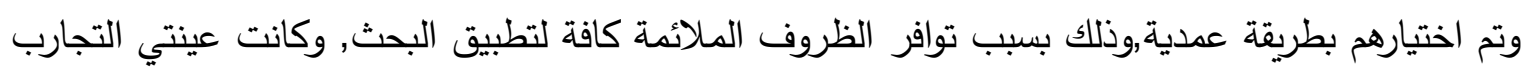
الاستطلاعية من ضمنها. r-r وسائل جمع البيانات

استخدم الباحثان الوسائل الأتية : تحليل المصادر , والبحوث, و الاستبيان, و الاختبارات.

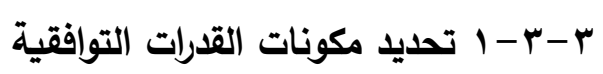
على الرغم من تعدد مكونات القدرات التوافقية التي ذكرتها المصادر وتعددها تبعاً لنوع النشاط الرياضي

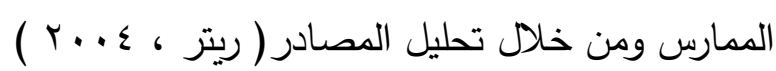

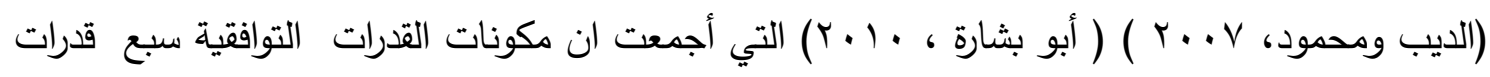

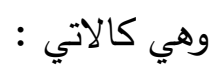
1- القدرة على تقدير (تحديد) الوضع. r- القدرة على الربط الحركي. ب- ب- القدرة على بذل الجها المناسب العركي ع - القدرة على الحفاظ على التوازن ○- القدرة على تغيير الاتجاه ( القدرة الايقاعية ) 1- القدرة على الاستجابة الحركية. V - القدرة على التكيف مع الأوضاع المتغيرة.

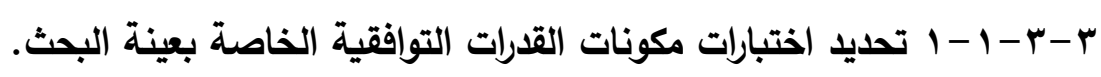

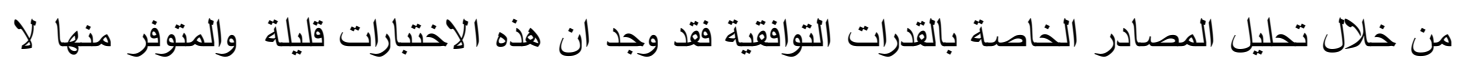

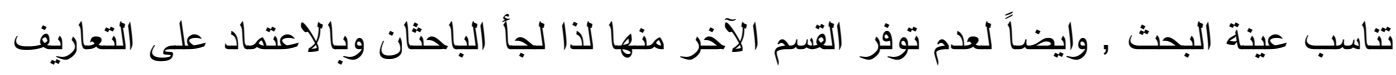

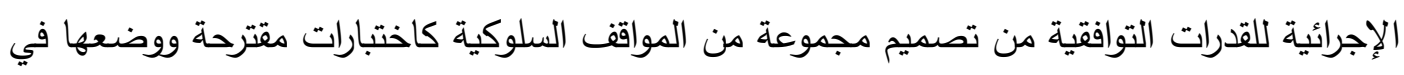

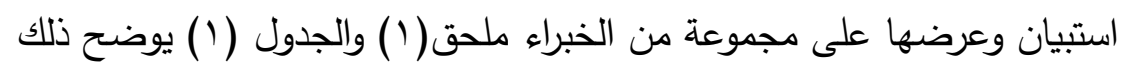




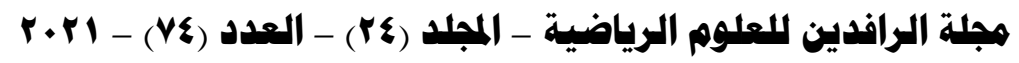

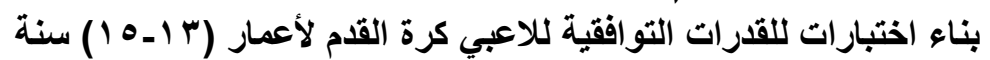

الجدول ( ) يبين نسب اتفاق الخبراء حول صلاحية الاختبارات المقترحة الخاصة بالقدرات التوافقية

\begin{tabular}{|c|c|c|c|}
\hline النسبة المئوية & لا يصلح & يصلح & القدرات التوافقية والاختبارات \\
\hline 91.7 & 1 & 11 & 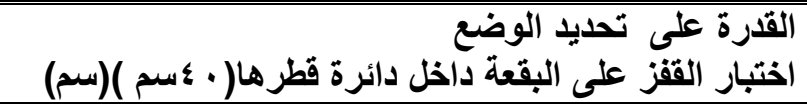 \\
\hline Ar.ru & r & 1. & القتبار جمع الكرات (ثثانيةً) \\
\hline (Mr.ru & r & 1. & القتبرة إصابة المسطبة بالكرة من مسافات متعددة (درجة) \\
\hline vo & $r$ & 9 & القتبار التوازن الحفاظ على التوازن بإحدى القدمين ^ م (ثانية) \\
\hline r.r.ru & $r$ & 1. & 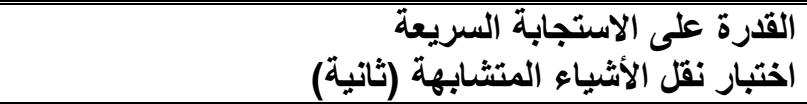 \\
\hline r.r.r & r & 1. & 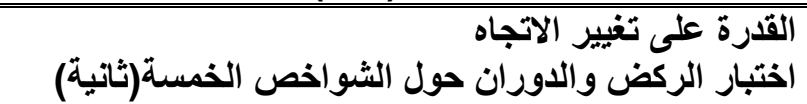 \\
\hline vo & $r$ & 9 & القتبرة الاركاض التكيف مع المتوعة (ثأنية) المتغيرة \\
\hline
\end{tabular}

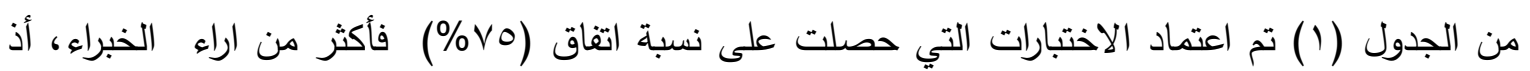
يثير ( بلوم وآخرون ، به9 () الى أن على الباحث الحصول على نسبة اتفاق \% \% فأكثر من اراء الخبرا

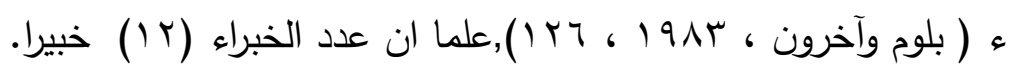

r- بـ التجارب الاستطلاعية

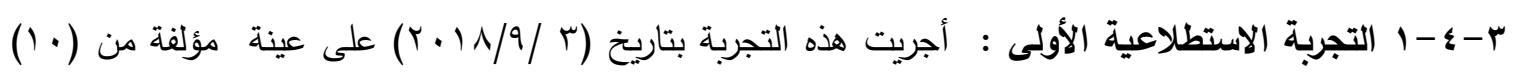
لاعبين من عينة البحث وكان لها اهداف إدارية وتنظيمية.

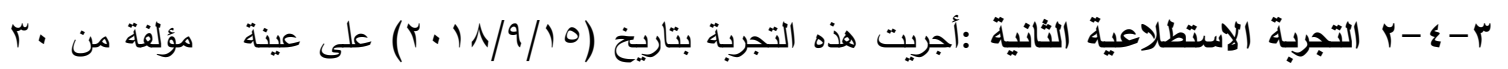

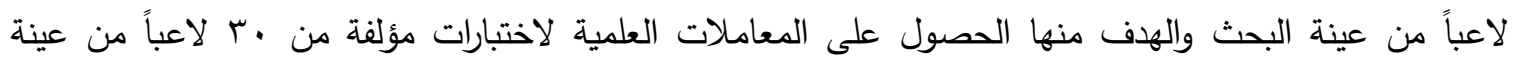

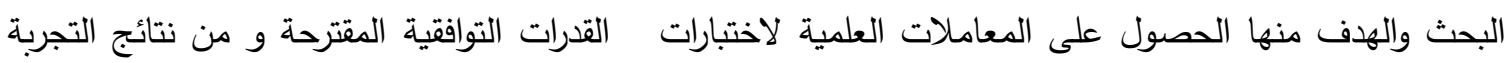
الحصول على بيانات اداء العينة على الاختبارات للحصول على التطبيق الاول لهعامل الثبات وحساب معامل الالتواء للاختبارات . ثم قام الباحثان بإعادة تطبيق الاختبارات بعد مرور أسبوع على العينة نفسها وبالثروط نفسها اجراء التطبيق

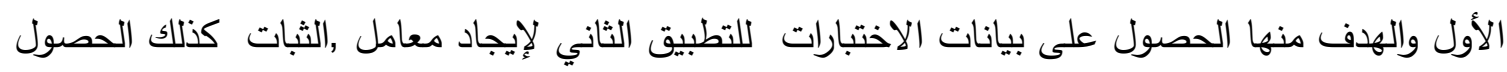
على معامل الموضوعية . r - ه المعاملات العمية للاختبارات المقترحة الخاصة بالقدرات التوافقية. r-ه - صدق الاختبارات :استخدم الباحثان أنواع عدة اذ استخدم الصدق الظاهري للاختبار , ومن ثم الصدق المنطقي (المحتوى) عن طريق الخبراء , والصدق الذاتي, والصدق التمييزي. 
يعني قدرة الاختبار على التثريق بين الأشخاص الذين يتمتعون بدرجة مرتفعة من الصفة ناحية وبين من

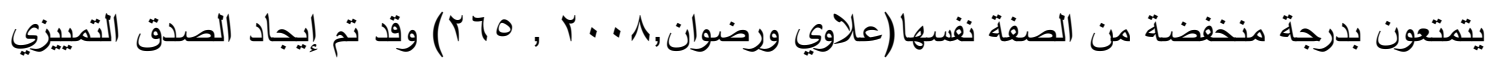
لكل اختبار بأسلوب المجموعتين المتضادتين, أذ تم تطبيق الاختبارات على (• (ץ) لاعباً ثم ترتيب درجات المختبرين في كل اختبار ترتيباً تنازلياً واعتمدت قيمة T لدلالة الفروق بين متوسطات المجموعتين العليا والدنيا لكل اختبار وجدول (r) يبين ذلك.

الجدول (ץ) يبين الفروق المعنوية بين المجموعة العليا والدنيا في متفيرات القدرات التوافقية

\begin{tabular}{|c|c|c|c|c|c|c|}
\hline \multirow[b]{2}{*}{ المعنوية } & \multirow[b]{2}{*}{ قالمتسبة T } & \multicolumn{2}{|c|}{ المجمو عة الدنيا } & \multicolumn{2}{|c|}{ المجمو عة العليا } & \multirow[b]{2}{*}{ الاختبارات } \\
\hline & & الالمعراري & الوسط الحسابي & الانحرياري & الوسط الحسابي & \\
\hline$\cdots$ & $-7 . r \vee 0$ & $1 . \wedge \wedge \varepsilon$ & r.orr & Y.IVV & $\Lambda . r .$. & $\mathbf{X} 1$ \\
\hline$\cdots$ & $-\wedge . \wedge \vee 1$ & I.MrI & 19.191 & 1.470 & $r r .001$ & $\mathrm{X} 2$ \\
\hline$\cdots$ & -9.0 .5 &.$v \cdot r$ & $0.9 r r$ &.$\wedge r \wedge$ & $1.7 \ldots$ & X3 \\
\hline$\cdots$ & $-\Lambda . . r$ & $7.0 \wedge \mathrm{V}$ & $r q . A v$ & V.00r & $04 . \vee 94$ & $\mathrm{X} 4$ \\
\hline$\cdots$ & $-1 \cdot . .91$ & $r \cdot \leq \wedge \wedge$ & $1 . .0 Y V$ & r.vq. & $11.89 \leq$ & $X 5$ \\
\hline$\cdots$ & $-V . V \cdot 0$ & $r . r \cdot V$ & $11.19 \leq$ & r.orr & I Y.VTE & X6 \\
\hline$\cdots$ & $-\wedge . \cdot \leq 1$ & 1.07 & $r r . \leq r \wedge$ & $9 . V \leq V$ & $Y Y . \& Y Y$ & $X 7$ \\
\hline
\end{tabular}

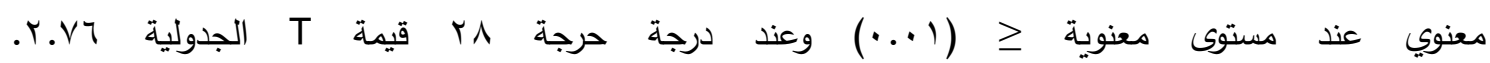
يبين الجدول (Y) أن هنا فروق معنوية في اختبارات القدرات التوافقية الخاصة بعينة البحث بين لاعبي المجموعتين العليا والدنيا ,وذلك من خلال مقارنة قيمة (T) المحتسبة مع قيمتها الجدولية وهذا يدل على ان الاختبارات قادرة على التمييز بين المجوعتين المتضادة.

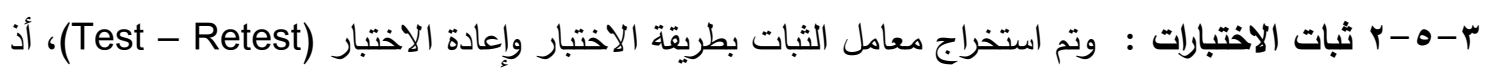

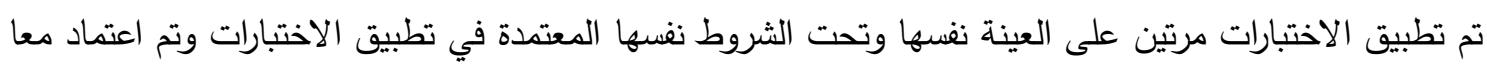

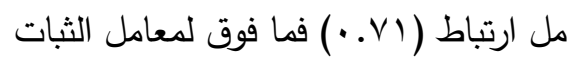
r - - - م موضوعية الاختبارات: تم استخراج معامل الموضوعية عن طريق إيجاد معامل الارتباط بين درجتي

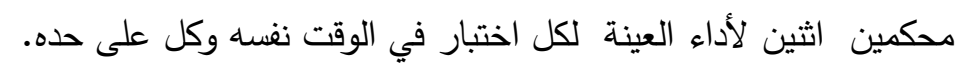

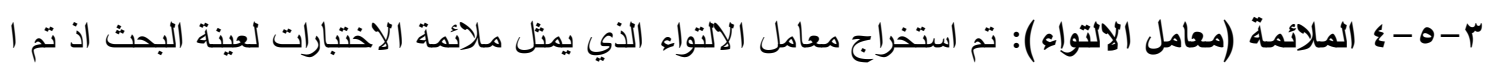

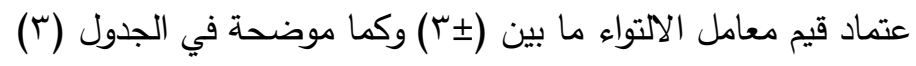




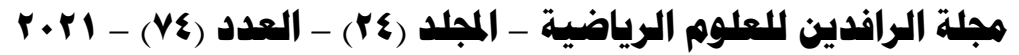

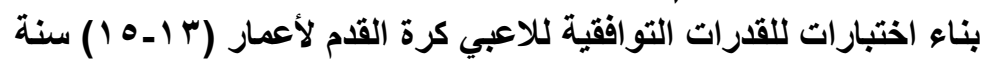

الجدول (r) يبين المعاملات العلمية لاختبارات القدرات التوافقية

\begin{tabular}{|c|c|c|c|c|}
\hline الالتواء & الموضوعية & الأتي & 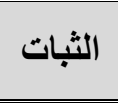 & اختبارات القدرات التوافقية \\
\hline$\cdot r \cdot V$ & 1 & $\cdot \wedge \neg 1$ & $\cdot V \varepsilon r$ & اختبار القفز على البقعة داخل دائرة قطرها (• ـسم) \\
\hline. $.1 \%$. & $\cdot .9 \wedge 9$ & $\cdot \wedge \vee 1$ &.$\vee \vee$ & اختبار جمع الكرات (ثانية) \\
\hline. $.1 V r$ & 1 & $\cdot . \wedge \neg 7$ & 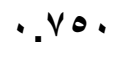 & اختبار اصابة المسطبة بالكرة من مسافات متعددة (درجة) \\
\hline $1.1 \%$ & $\cdot .9 \vee V$ & $\cdot \wedge 91$ & $\cdot \vee \vee \leq$ & اختبار التوازن المتحرك بالحجل بإحدى القدمين مسافة ^م (ثانية) \\
\hline$\because \vee \vee q$ & .999 & $\cdot . \wedge 9 r$ &.$\vee \vee \vee$ & اختبار نقل الاشياء المتثابهة (ثانية) \\
\hline. .47 & $\cdot .990$ & $\cdot .9 \leq 1$ & $.9 \ldots$ & اختبار الركض والدوران حول الثواخص الخمسة (ثانية) \\
\hline $.1 \leqslant$. & $.99 \leq$ & $\cdot \wedge \bullet 9$ & $\cdot . \vee r q$ & اختبار الاركاض المتنوعة (ثانية) \\
\hline
\end{tabular}

ب- " التنفيذ النهائي لاختبارات البحث: بعد التأكد من توفر المعاملات العلمية للاختبارات تم تطبيق الاخ تبارات على عينة البحث

ب-V المعالجات الإحصائية. تم استخدم البرنامج spss في ايجاد الوسط الحسابي ، والانحراف المعياري

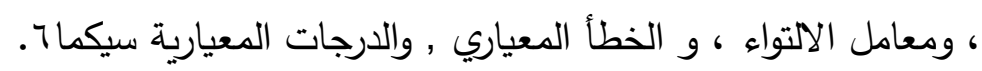

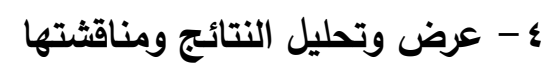

ع - 1 الوصف الاحصائي لاختبارات القدرات التوافقية الخاصة بعينة البحث.

الجدول (؛ ) يبين المعالجات الإحصائية لاختبارات القدرات التوافقية لعينة البحث

\begin{tabular}{|c|c|c|c|c|}
\hline $\begin{array}{r}\text { المعياري } \\
\end{array}$ & معامل & الالحعرافي & الوسطابي & اختبارات القدرات التوافقية \\
\hline$\cdot r \cdot r$ & $\because$ YO & $r . A v$ & 0.794 & اختبار القفز على البقعة داخل دائرة قطرها ( • عـم) \\
\hline .YYT & $-\cdot Y V Y$ & Y.71 & YM.MOH & اختبار جمع الكرات (ثانية) \\
\hline. $.1 \mathrm{TV}$ &..$\$ 71$ & $1 . r 91$ & V.VII & اختبار إصابة المسطبة بالكرة لمسافات متعددة (درجة) \\
\hline 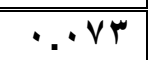 & $-\cdot .9 \wedge r$ & $. . V \leqslant q$ & $9.1 \leqslant 0$ & اختبار التوازن المتحرك بالحجل بإحدى القدمين مسافة ^م (ثانية ) \\
\hline .101 & $-\cdot .0 \leqslant \Lambda$ & $1.0 \leq \leqslant$ & $Y \varepsilon . \varepsilon \wedge 1$ & اختبار نقل الأشياء المتشابهة (ثانية) \\
\hline. .97 & $\cdot . r \cdot 1$ & $. .7 V \leq$ & IY.IY & اختبار الركض والدوران حول الثواخص الخمسة (ثانية) \\
\hline$\because 74$ & .1 .9 &. .701 & $11 . \cdot \leq V$ & اختبار الاركاض المتنوعة (ثانية) \\
\hline
\end{tabular}

يتضح من الجدول رقم (§) ان قيم الأوساط الحسابية قد تجاوزت الانحراف المعياري, وهذا يعد احد مؤشرات انتظام

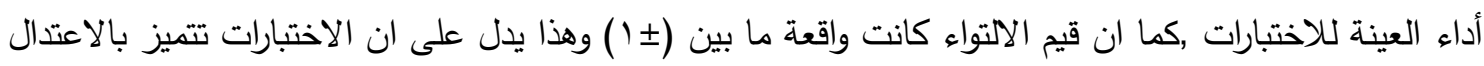

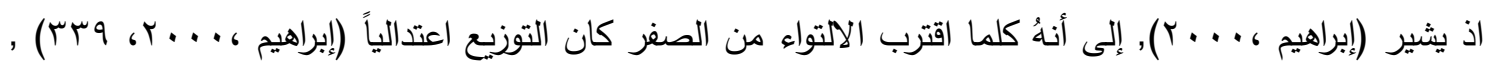
وان قيم الخطأ المعياري كانت واطئة. ع - ب المواصفات الكاملة للاختبارات القدرات التوافقية والدرجات المعيارية لهاتيات اختبار القفز على البقعة داخل دائرة قطرها ـعسم. الغرض من الاختبار : قياس القدرة على تحديد الوضع. 


$$
\text { الادوات المستخدمة: شريط قياس , وطباشير. }
$$

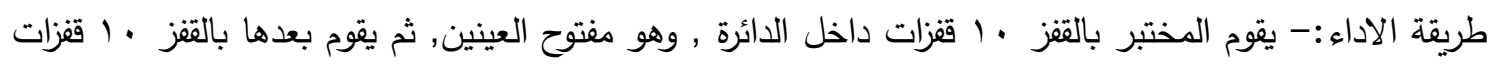
داخل الدائرة وهو مغلق العينين. التسجيل: تحسب مسافة انحراف مقدمة القدم البعيدة عن محيط الدائرة بالسم للقفزة الاخيرة بعد الثبات.

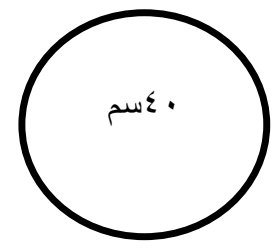

\begin{tabular}{|c|c|c|c|c|c|}
\hline المعيارية & الارجة & المعيارية & الارجة & المعيارية & الارجة \\
\hline$r V .0 \leqslant Y$ & 1 & $70 . V Y 9$ & $\varepsilon$ & $\Lambda \cdot . \vee Y q$ & . \\
\hline$\left.r T_{.}\right) \leqslant \varepsilon$ & 9 & Or.VTV & 0 & VO.VTN & 1 \\
\hline$r 7 . V \leqslant 0$ & 1. & $\varepsilon \Lambda . r \mu q$ & 7 & VO.ru & $T$ \\
\hline$r) r \leqslant V$ & 11 & కr.9ミ1 & V & $79.94 \%$ & $r$ \\
\hline
\end{tabular}

الجدول (•) يبين الدرجات الخام والدرجات المعيارية لاختبار القفز على البقعة داخل دائرة قطرها ـــ سم

اختبار جمع الكرات.

$$
\text { الغرض من الاختبار : قياس القدرة على الربط الحركي. }
$$

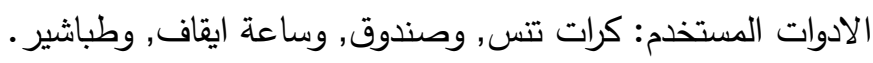

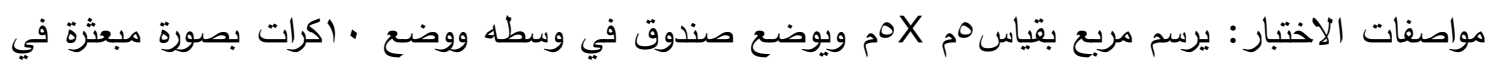

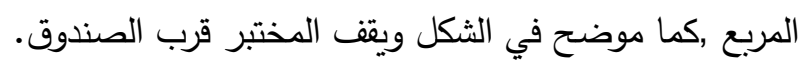

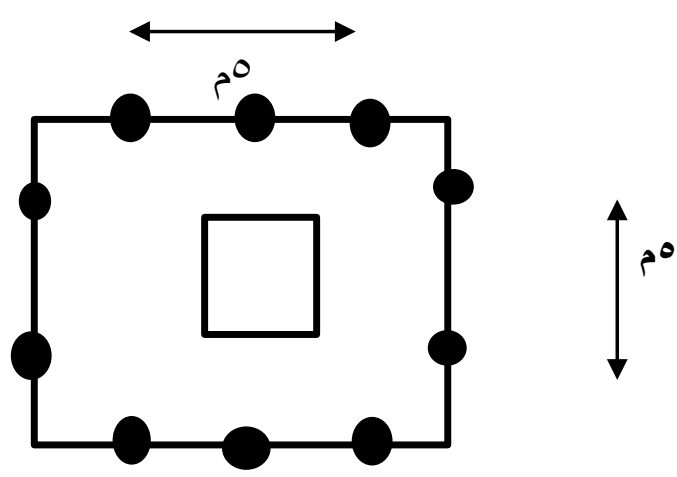

شكل الاختبار

طريقة أداء الاختبار : عند سماع المختبر إشارة البدء يقوم بجمع كرات التنس العشر المبثثر ووضعها في الصندوق. التسجيل: احتساب الزمن الكلي لأداء الاختبار . 


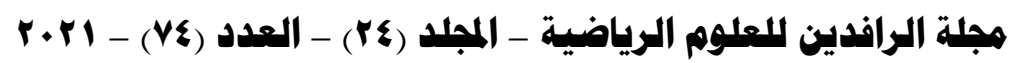

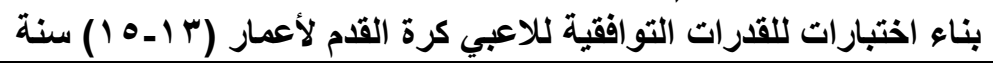

الجدول (†) يبين الارجات الخام و درجات المعيارية لاختبار جمع الكرات (ثانية)

\begin{tabular}{|c|c|c|c|c|c|c|c|}
\hline اللارجة المعيارية & الارجة & المعيارية & الارجة & المعيارية & الدرجة & المعيارية & الارجة \\
\hline rV.Y01 & ro.s) & $\{7.71$ & rT.q & $7 . \leqslant \wedge \varepsilon$ & TI.0 & NT.V97 & 18.9 \\
\hline$T \leq .0 Y \leqslant$ & ro.10 & $\leqslant 0.99$ & $T \varepsilon$ & $7 . .09$ & YI.VT & $V 9.197$ & 11.71 \\
\hline ס & YY.Y & 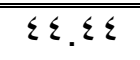 & Yะ.YO & $01 . \cdot V 7$ & TY.0 & 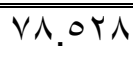 & $11 . .80$ \\
\hline$r \wedge .9 \leq 7$ & rY.Vo & $\left\{Y_{0} 0 \leqslant 1\right.$ & $r \leqslant .00$ & 00.097 & YY. $\leqslant 0$ & VT.RT & 19.10 \\
\hline rV.rqV & TV & $\left.\sum Y . Y Y\right)$ & $r \leqslant .7$ & Or.VTV & YY.YO & 79.101 & $r .10$ \\
\hline rч.Arq & $r V .+q$ & $\{1.971$ & $r \leqslant .70$ & or.71s & TY.9T & $T V . r V T$ & $r \cdot .00$ \\
\hline Y . VVV & $r V .1$ & $\varepsilon \cdot .1 \cdot r$ & $r \leqslant .90$ & Or.1A1 & TT & $77 . V O Y$ & $T \cdot .70$ \\
\hline ro.1.r & PrV.rV & rq.V9r & ro & $0 . \mathrm{TY \Lambda}$ & Tr.T & $70.7 \mathrm{rV}$ & $\overline{T \cdot . \wedge r}$ \\
\hline$r \leq . r q \wedge$ & rV.O & $r 1.00 r$ & YO. & $\leqslant q . r \mu q$ & rr. & $7 \leqslant .879$ & $r \cdot .9 V$ \\
\hline "Yr.IYA & TV.Ao & $\overline{R V . r I r}$ & ro.s & $29 . \wedge 9$ & Tr.o & $\overline{T I \Sigma, Y V T}$ & TI..0 \\
\hline
\end{tabular}

اختبار التوازن المتحرك بالحجل بإحدى القدمين مسافة ^ م الغرض من الاختبار : قياس التوازن المتحرك. ادوات مستخدمة: ساعة ايقاف, وطباشير مواصفات الاختبار : يرسم خطان متوازيان طول كل منهما ^م والمسافة بينهما • باسم طريقة اداء الاختبار: يقوم المختبر بالحجل بإحدى القدمين لمسافة ^ م ذهاباً والرجوع بالحجل بالقدم الاخرى لمسافة ^م م اياباً التسجيل: احتساب الزمن الكلي للذهاب والاياب واضافة ثانية لكل خطأ مثل لمس الخط أو الخروج عنه.

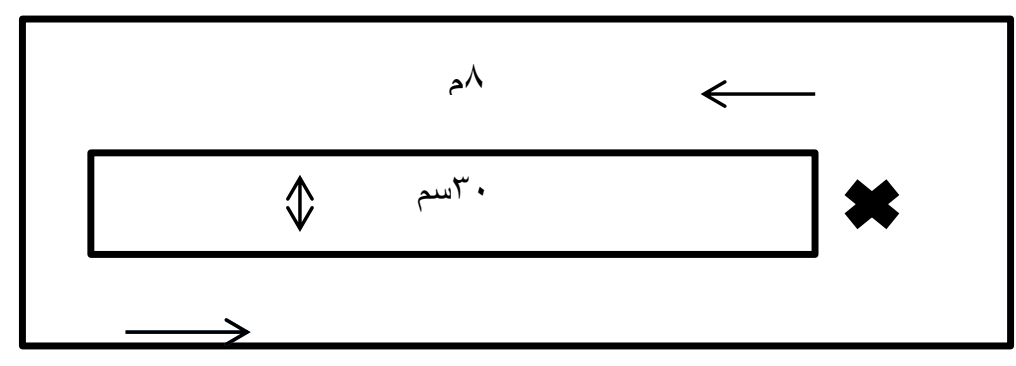

شكل الاختبار 


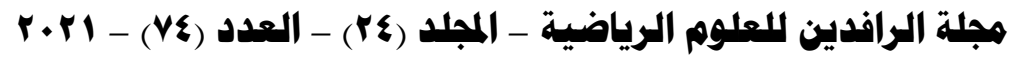

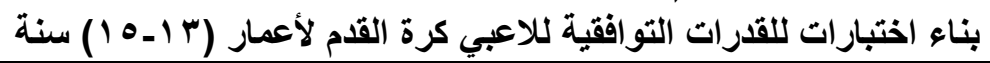

الجدول (V) يبين الارجات الخام والدرجات معيارية لاختبار التوازن المتحرك بالحجل (ثانية)

\begin{tabular}{|c|c|c|c|c|c|c|c|}
\hline المعيارية & الخام & المعيارية الدرجة & الارجة & المعيارية الدرجة & الارجة & المعيارية & الخام \\
\hline$\varepsilon Y .1 .7$ & 7.0 & $01.7 V T$ & $7 . V$ & Ir. r & 0.00 & ᄉ $\wedge \leqslant . \Gamma \vee q$ & $\varepsilon .7$ \\
\hline$\varepsilon . . V \vee I$ & 7.07 & $01 . .00$ & 7.1 & Tr.Ir. & 0.7 & $\Lambda I . \leqslant r$ & $\varepsilon . \vee 0$ \\
\hline 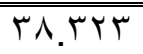 & $7.7 \mathrm{~V}$ & 0.117 & $7.1 \leq$ & $71 . Y \leq$. & $0.7 \varepsilon$ & $V V . V .0$ & $\varepsilon .9$ \\
\hline TV.707 & $7 . V$ & ะ & 7.10 & 71.11 & 0.70 & VV.RV & $\varepsilon .9 \mu$ \\
\hline וץ. & 7.87 & $\leq 9.7 \vee 1$ & 7.17 & $09 . Y$ M & $0 . V T$ & VT.YOO & 0.1 \\
\hline ro.AVt & $7 . \vee \wedge$ & $\varepsilon \wedge . \vee \wedge)$ & $7 . r$ & OV. . & 0.1 & VI. r. & $0 . r$ \\
\hline To.70 & 7.19 & 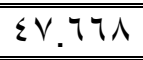 & 7.10 & 07.071 & 0.10 & $79.91 \mathrm{~V}$ & $0 . Y_{0}$ \\
\hline To.కT) & $7 . \wedge$ & 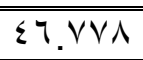 & 7.19 & $00.9 \ldots$ & $0 . \wedge \Lambda$ & $79 . \xi V Y$ & $0 . Y V$ \\
\hline$\Gamma \leq .0 \leqslant 1$ & $7 . \wedge \varepsilon$ & $\leqslant 7.007$ & $7 . r$ & $00.7 \mathrm{VA}$ & 0.19 & $7 V .794$ & $0 . \mu_{0}$ \\
\hline T.Y.T & 7.9 & $\leq 0 . \wedge \wedge \wedge$ & "ז. & $00 . \leqslant 00$ & 0.9 & 77.01. & 0.5 \\
\hline W. IVI & 7.97 & $\varepsilon 0 . \leqslant \leqslant \mu$ & 7.10 & $0 \leqslant . \Gamma \leqslant \mu$ & 0.90 & $7 \leqslant .100$ & 0.0 \\
\hline YI. EY & 7.91 & (I & $7 . \varepsilon$ & Or.r. & 7 & או & 0.01 \\
\hline$r .9 \wedge 1$ & $\mathrm{~V}$ & EY.997 & $7 . \leqslant 7$ & or.111 & 7.0 & 74.91. & $0.0 Y$ \\
\hline
\end{tabular}

اختبار اصابة المصطبة بكرة القدم من مسافات متعددة.

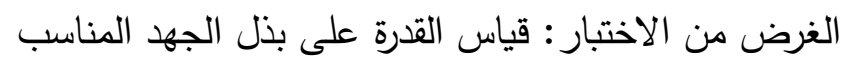
الادوات المستخدمة: · ل1 كرات قدم, وخمس شواخص , ومصطبة طول ام وارتفاعها ·عسم مواصفات الاختبار: يتم رسم خطوط بطول 0.5 م تبعد عن المصطبة سم ، 0م ، الم ، لم ، وم وتشكل زوايا مع منتصف المصطبة كما موضح بالثكل. طريقة اداء الاختبار: يقوم المختبر بضرب الكرة بداخل القدم (•( كرات )باتجاه المصطبة من مسافات متعددة لكل مسافة كرتين وكما في الثكل من مسافة سم و 0م و لم و طريقة التسجيل: احتساب درجة لكل ضربة صحيحة تلمس المسطبة من • ( كرات - الكرة التي لا تلمس المسطبة تعد خطأ وتحتسب صفر . - الكرة التي تلمس المسطبة تعد صحيحة وتحتسب درجة واحدة.

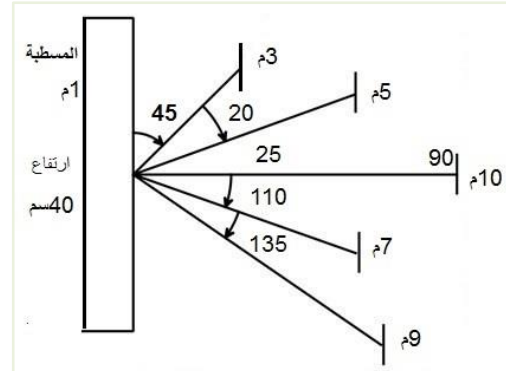

شكل الاختبار

الجدول (^) يبين الدرجات الخام والدرجات معيارية لاختبار اصابة المسطبة (درجة)

\begin{tabular}{|c|c|c|c|c|c|c|c|}
\hline المعيارية & الأرجة & المعيارية & الأرجة & المعيارية & اللخام & المعيارية & الارجة \\
\hline Qร.Y०Y & 1. & $0 \wedge . \Sigma \Lambda \varepsilon$ & 1 & rی.Tr & 7 & KY.V10 & $\varepsilon$ \\
\hline & & $V \cdot \ldots \cdot V$ & 9 & $\leq 7.07)$ & V & $r \Lambda . V 10$ & 0 \\
\hline
\end{tabular}


الغرض من الاختبار : قياس القدرة على المرونة الحركية

مواصفات الاختبار : توضع شواخص كما موضح بالشكل طريقة اداء الاختبار : عند الاشارة يقوم المختبر بركض مستقيم ,ثم يدور حول الثاخص, وينتقل الى الجهة اليسرى بخطوات جانبية ,ثم يدور من حول الثاخص, ويقوم الرجوع الى الوراء, ويدور حول الثاخص ,ثم ينطلق الى الامام, ويدور حول الثاخص, وينتقل الى جهة اليسرى وبخطوات جانبية ,ويدور حول الثاخص, ويرجع الى الوراء بخطوات خلفية ,ثم يدور حول الثاخص ,ثم ينتقل الى نقطة الانطلاق

بخطوات جانبية الى اليمين ,وكما موضح في الشكل. لتسجيل: يحتسب الزمن للأداء الكلي واضافة على خطا يرتكبه المختبر .

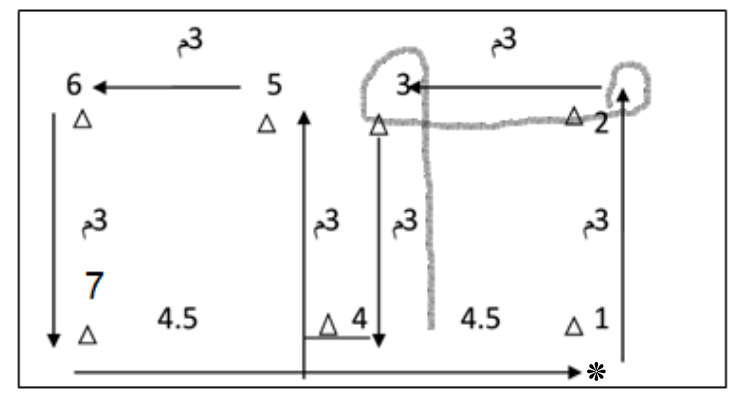

شكل الاختبار

\section{البداية والنهاية}

الجدول (9) يبين الدرجات الخام ودرجات معيارية لاختبار الاركاض المتنوعة(ثانية)

\begin{tabular}{|c|c|c|c|c|c|c|c|}
\hline اللدرجة المعيارية & الارجة الخام & المعيارجة المية & الألةهة & اللدرجة المعيارية & الارجة الخام & اللدرجة المعيارية & الارجة الخام \\
\hline T. $7 \leq 1$ & $11.0 \mathrm{~V}$ & $\leqslant 9 . \leqslant Y V$ & 11.2 & $7 . .17 \mathrm{~V}$ & $1 . .70$ & $94.1 T$ & $9 . \varepsilon$ \\
\hline To.AvE & 11.7 & รᄉ. ๆ . & 11.1 & 09.707 & $1 . .7 \mathrm{~V}$ & $9 . .10 \%$ & $9 . \leqslant 0$ \\
\hline$T \leqslant .097$ & 11.70 & $\varepsilon \vee . \wedge 9 T$ & 11.11 & $09.1 \leq \leqslant$ & $1 . .79$ & AT.।AI & 9.10 \\
\hline r. & $11 . V Y$ & $\varepsilon 7.1 \cdot r$ & 11.5 & $O \wedge . \wedge \wedge \Lambda$ & $1 \cdot . v$ & $\vee q . r \leq 7$ & 9.9 \\
\hline TI.OYV & $11 . V V$ & $\varepsilon \varepsilon . \wedge Y \leqslant$ & 11.50 & $0 V .71$. & $1 . .10$ & $V \cdot . \Gamma 97$ & 1. . \\
\hline$r \cdot . \vee \tau$. & 11.1 & $\varepsilon \varepsilon . .0 V$ & $11 . \mathrm{rA}$ & OV.TOS & $1 \cdot . v 7$ & $79 . \wedge \wedge \leq$ & $1 \cdot Y V$ \\
\hline rq. $\leqslant \wedge r$ & 11.10 & $\leqslant r .0 \leqslant 7$ & $11 . r$ & וT.M & $1 \cdot .1$ & 79.118 & $1 \cdot r$ \\
\hline Y7.9Y & 11.90 & $\leqslant T .0 \leqslant 7$ & 11.1 & $00 . \wedge Y$. & $1 \cdot . \wedge r$ & 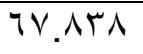 & $1 \cdot .10$ \\
\hline r7.9Yร & 11.90 & $\varepsilon r . \vee \vee q$ & אז.11 & $00.07 \leq$ & ני & $7 V . \cdot V I$ & $1 . \Gamma$ \\
\hline rч. & $11.9 \mathrm{~V}$ & E1.V07 & $11 . r v$ & 00.04 & 1.10 & $77 . \wedge 17$ & q. \\
\hline ro. $7 \leq 7$ & 14 & $\varepsilon 1 . r \leq \varepsilon$ & 11.19 & or...V & 1.91 & 77.07. & $1 \cdot .5$ \\
\hline $4 r .19$ & $1 Y .1$ & $\varepsilon . .9 \wedge 9$ & $11 . \varepsilon$ & or $\leqslant 97$ & 1.90 & $70 . Y \wedge 1$ & $1 . \leq 0$ \\
\hline YI.AI. & $1 Y .10$ & 19.199 & $11 . \varepsilon V$ & $01 . Y 1 \mathrm{~V}$ & 11 & $7 \varepsilon . . . T$ & 1.0 \\
\hline$r . . O r r$ & IY. & 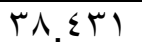 & 11.0 & $0 . . V \cdot T$ & 11.4 & TY.VYE & $1 . .00$ \\
\hline 19.501 & IT. & rV.10r & 11.00 & $0.19 \leq$ & $11 . \varepsilon$ & TוY & $1 . .0 \mathrm{~V}$ \\
\hline $1 V .9 \vee \varepsilon$ & IT & rч. & 11.07 & $\varepsilon 9.949$ & 11.0 & $71 . \leq \leqslant 7$ & 1.7 \\
\hline
\end{tabular}




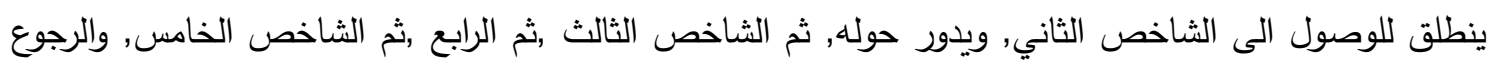

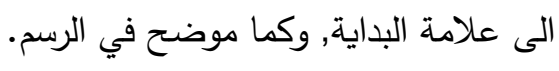
التسجيل: يحتسب الزمن المستغرق للأداء.

* البداية والنهاية

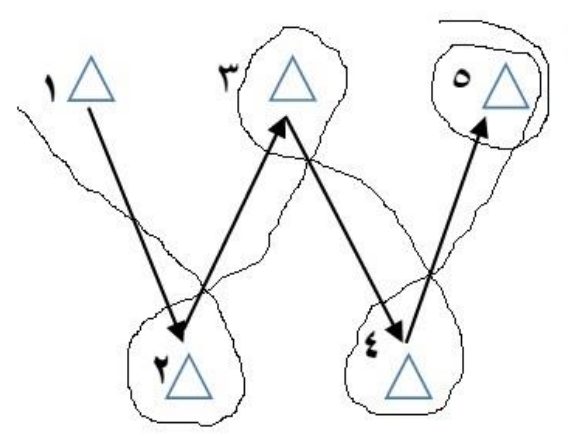

شكل الاختبار

الجدول ( • (1) يبين الدرجات الخام والدرجات المعيارية لاختبار الركض والدوران حول الثواخص الخمسة (ثانية)

\begin{tabular}{|c|c|c|c|c|c|c|c|}
\hline المعيارية الارجة & الألة الخام & المعيارية & الارجة الخام & المعيارية & اللخام & المعيارية & الارجة \\
\hline$r V . Y \leq T$ & $1 T .70$ & דוץ. & IT & IT.V.. & 11.01 & $10.90 \mathrm{Y}$ & $1 . .71$ \\
\hline ד.V01 & IT.TV & 04.79 & $1 T .1$ & Tr. & 11.09 & $\wedge r . \leqslant \vee q$ & $1 . \mathrm{VA}$ \\
\hline r.. & IT.V & OY.AYY & IT. & TY. YIV & $11.7 \varepsilon$ & $\vee q . Y \vee T$ & 1.90 \\
\hline To.ru & IT.VT & or.. A. & $1 T .0$ & $71.9 V$. & 11.70 & VA.VAr & $1 . .9 V$ \\
\hline$r \varepsilon . r \vee q$ & IT.VV & $0 . \wedge \leq \leqslant$ & $1 Y .1$ & T . & 11.2 & VV.Vqr & 11.1 \\
\hline ו.r. & IT.10 & $\leqslant 9.7 .1$ & $1 T .10$ & $09 . \leqslant 9 V$ & 11.20 & $V \varepsilon . \wedge Y \nearrow$ & 11.11 \\
\hline 1. & 19.9 & $\leqslant \wedge . \wedge \neg 7$ & $1 Y .11$ & $09 . \leqslant 9 V$ & 11.20 & VT.AKV & $11.1 \mathrm{~V}$ \\
\hline$\Gamma . \wedge 1 \wedge$ & $\mid r .91$ & $\varepsilon \wedge . r \vee Y$ & IT.Y & 09.10. & 11.87 & ס Vו. VI & $11 . r V$ \\
\hline$r . .0 V$. & Ir. 94 & $\leq 7.7 \leq 1$ & IT.YV & $09 . .1$ & $11.8 V$ & 81.111 & $11 . \mathrm{r}$ \\
\hline$r q . \wedge r q$ & 11.90 & $\leqslant 7.1 \leq 7$ & Ir. & $01 . V 04$ & $11.8 \wedge$ & $V . \wedge V$. & 11.19 \\
\hline rᄉ.09r & 11 & $\leqslant 0.10 \mathrm{~V}$ & سז.rו & or.YYI & 11.1 & V. & $11 . r$ \\
\hline$r \pi . \wedge 7 r$ & Ir.V & $\varepsilon \varepsilon .77 \pi$ & סח.rו & OT.0T. & $11 . \wedge \mathrm{V}$ & $79 . \mu \wedge V$ & ס. 11. \\
\hline YT.IT. & $1 \pi .1$ & $\{r .9 Y)$ & IT.M & $07 . Y \wedge \mu$ & $11 . \wedge 1$ & $7 \wedge . \wedge 9 \%$ & $11 . r v$ \\
\hline$Y \varepsilon . \wedge \wedge \varepsilon$ & 11.10 & EY.191 & IT. $\leqslant 0$ & $00 . \vee \wedge 9$ & 11.9 & $7 V . \varepsilon \cdot 9$ & $11 . \leqslant \pi$ \\
\hline$r \leqslant . r \wedge q$ & IT. & $\varepsilon 1.9 \leq r$ & IT. $\leqslant 7$ & $0 \leq . \wedge \ldots$ & $11.9 \leq$ & $7 V .17 Y$ & $11 . \varepsilon \varepsilon$ \\
\hline$r .7 \leq \Lambda$ & T.Y & 51.797 & IT. $\leqslant V$ & $0 \leqslant .001$ & 11.90 & $70.7 \mathrm{VA}$ & 11.0 \\
\hline 19.949 & סז. & $\varepsilon .90 \leqslant$ & IT.O & $0 \leqslant . \Gamma .0$ & 11.97 & $70 . \leqslant 1$ & 11.01 \\
\hline 17. VYO & $1 T . \varepsilon \wedge$ & סT.r. & $1 Y .71$ & or.AII & 11.91 & $7 \varepsilon .9 T V$ & 11.04 \\
\hline IITIYI & 15.0 & $r \vee .9 \wedge \wedge$ & IT.Tr & or.07ร & 11.99 & $7 r .9 \leqslant 1$ & $11.0 \mathrm{~V}$ \\
\hline
\end{tabular}




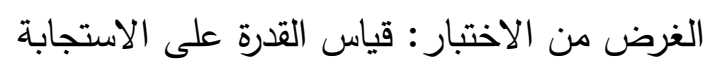

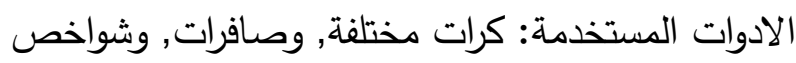
مواصفات الاختبار : يرسم خطان متوازيان بطول عم والمسافة بينهما سم توضع الاشياء على الخط الاول ,اما الخط الثاني توضع الاشياء المتثابهة عليه بثكل مختلف, ويقف المختبر بالوسط بين الخطين كما موضح في الثكل

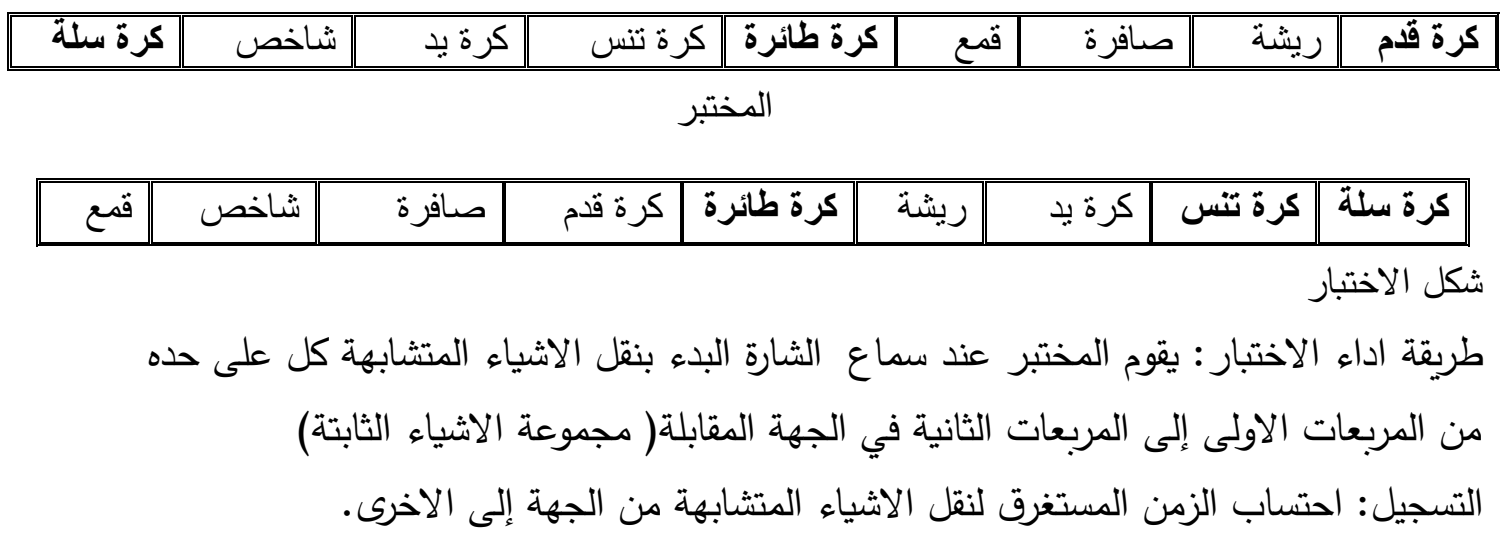

الجدول (11) يبين الدرجات الخام والدرجات المعيارية لاختبار نقل الاثياء المتشابهة (ثانية)

\begin{tabular}{|c|c|c|c|c|c|c|c|}
\hline المعيارية & الارجة & المعيارية & الخام & المعيارية & الارجة & المعيارية & اللارجة \\
\hline rV.qTा & Y0.7 & $\leqslant 9 . \cdot \leqslant 9$ & $r \leqslant .0 V$ & $7.7 \ldots$ & Tr.o & 1.5 .419 & $19 . \leqslant 0$ \\
\hline rV.rql & 10.70 & $\Sigma \wedge . \vee Y O$ & $T \leq .7$ & $0 \vee .710$ & Tr.VV & 91.941 & 19.90 \\
\hline rצ.rוा & YO.VO & $\overline{\varepsilon \wedge .1 \wedge \uparrow}$ & $r \leqslant .70$ & OV.rTI & $r r . \wedge$ & 9 9T.OY & $r \cdot . \leqslant 0$ \\
\hline $1 \% 0.17$ & YO.AV & 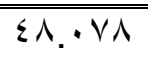 & $Y \leqslant .77$ & $0 V .1 \leqslant 0$ & TY.AT & 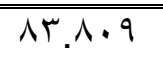 & T. \\
\hline Tr.TाT & YT & $\leqslant V .7 \leqslant 7$ & $r \leqslant . V$ & 07.97 & rT.qT & $\lambda \cdot . r$. & YI.V \\
\hline Tr.TIV & YT.IT & 57.077 & $r \leqslant . \wedge$ & $00 . V \leqslant Y$ & Tr.90 & $\overline{V V . A V I}$ & YI.9 \\
\hline $1.99 \mu$ & r7.10 & $\leqslant 0 . \wedge ! 1$ & $r \varepsilon . \wedge V$ & $00.74 \leqslant$ & Tr.9T & VI.V9Y & $\overline{T Y}$ \\
\hline$r \cdot .91 \leqslant$ & YT.YO & $\leqslant 0 . \leqslant \wedge V$ & $r \leqslant .9$ & $00 . \mu 1$. & Tr.9q & VO.VIY & TY.I \\
\hline$\Gamma \cdot . r v \varepsilon$ & r..r & «ร.VTा & $r \leqslant .9 V$ & $00 . Y \cdot Y$ & Ts & $79.77 \mathrm{~V}$ & TY.TT \\
\hline Yq.Y90 & rY.\& & Eక . TYT & $r \leqslant .9 \wedge$ & OS.YM & r 5.9 & 79.009 & $\overline{P Y T . T V}$ \\
\hline YA.YIO & r..0 & $\varepsilon \varepsilon . \varepsilon \cdot V$ & ro & or.0Nr & $r \leqslant .10$ & 79.Y & TY.V \\
\hline TV.TVO & $Y 7.00$ & ET.TYA & Yo.1 & or.TYV & Tะ.IV & $70 . \vee \wedge 1$ & $T r . T$ \\
\hline Yr.^qV & r7.9 & 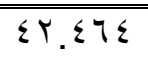 & ro.11 & or.. & $r \Sigma . Y$ & בז.MY & TY.YT \\
\hline YY.YVA & $Y V_{.0} .0$ & $E Y . Y \leqslant \Lambda$ & ro.r & 01.107 & $r \leq . T$ & $7 \pi .5 .7$ & YT.Ys \\
\hline$Y I . \wedge \leqslant T$ & $r V .99$ & $\leqslant 1 . V \cdot 9$ & YO. YO & $01 . Y \cdot 1$ & $T \Sigma . T V$ & Tr.YqA & TH.TO \\
\hline 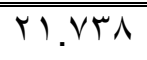 & TY.I & $\varepsilon \varepsilon .7 r q$ & ro.ro & $0 . \wedge \wedge \varepsilon$ & TI. & $\pi r \ldots r$ & $\overline{T r . r V}$ \\
\hline $19.0 \vee 9$ & YV.r & $\varepsilon \cdot . \Sigma) \Gamma$ & ro.rv & $0 . r \leqslant 0$ & $r \leq . \leq 0$ & 71.119 & $r T . \leqslant 0$ \\
\hline \multirow[t]{2}{*}{$1 \cdot .9 \leqslant r$} & r^.) & $\varepsilon . \mu .0$ & ro.rᄉ & $\varepsilon 9.91 \%$ & $r \leqslant . \leqslant q$ & $7.9 Y \varepsilon$ & $T r . \varepsilon V$ \\
\hline & & rq.. & TO.O & $\leqslant 9 . \wedge .0$ & $T \leqslant .0$ & $7 \cdot . V \cdot \Lambda$ & rr. $\leqslant q$ \\
\hline
\end{tabular}


• - - الاستنتاجات والتوصيات

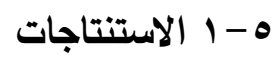

- التوصل الى مجموعة اختبارات تقيس القدرات التوافقية السبع وتتمتع بالمواصفات العلمية من صدق وثبات وموضوعية وملائمة. - التوصل الى الدرجات المعيارية لاختبارات القدرات التوافقية السبع. • - r r التوصيات

- - اعتماد الاختبارات التي تم التوصل اليها كوسائل لقياس مستوى القدرات التوافقية لانتقاء واختيار لاعبي كرة القدم الناشئين.

المصادر

1. إبراهيم، احمد محمود ححمد (. . ب): التمايز والاسهام النسبي لبعض الدلالات البيولوجية والبدنية والمهارية للاعبي مسابقة القتال (الكاتا) المميزين وغير المميزين كمحدد للانتقاء والتصنيف برياضة التئة الكاراتية ، المجلة

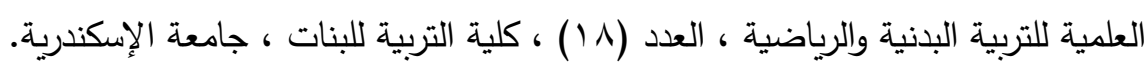

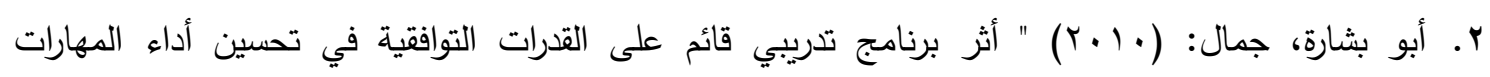
الأساسية لناشئ كرة القدم "، رسالة دكتوراه غير منشورة، كلية التربية الرياضية، الجامعة الأردنية.

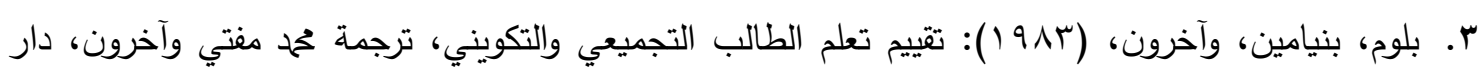
ماكروهيل، القاهرة.

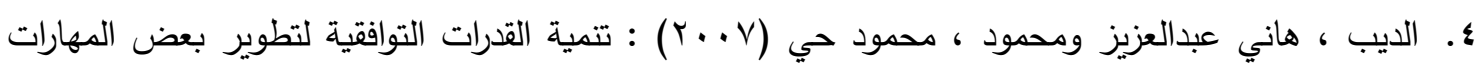

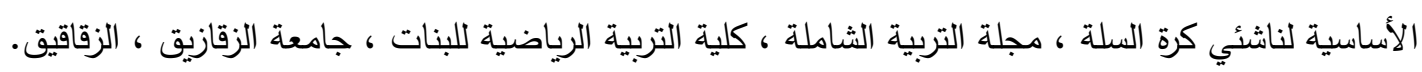

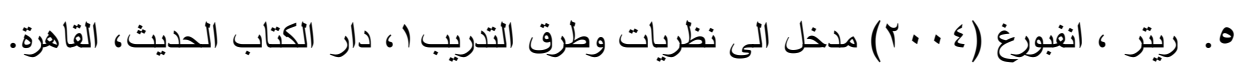

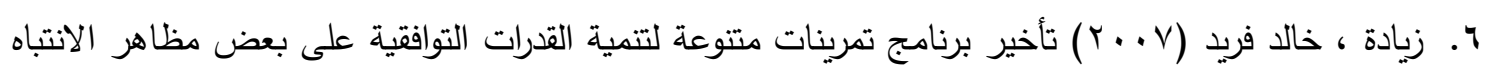

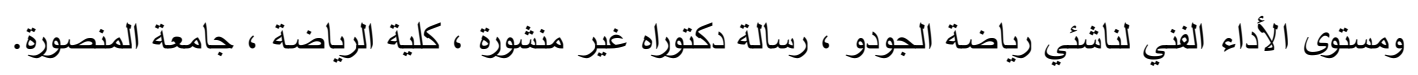

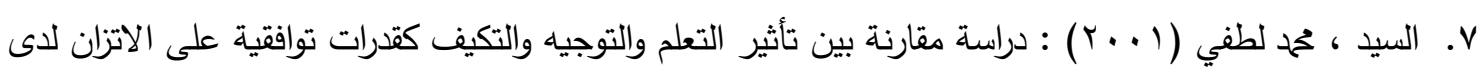

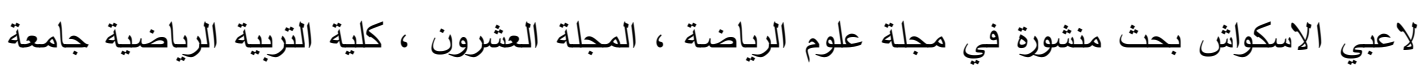
المنيا.

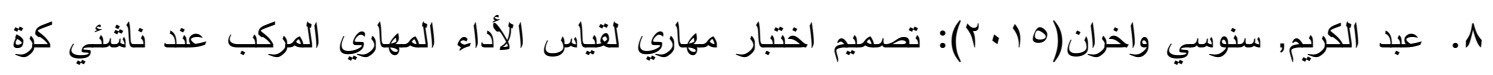

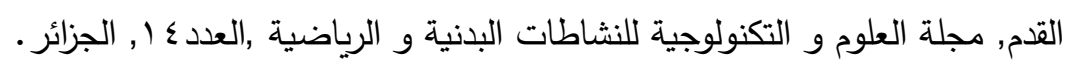

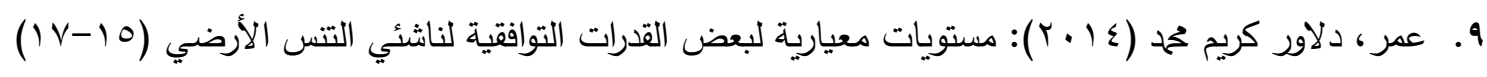

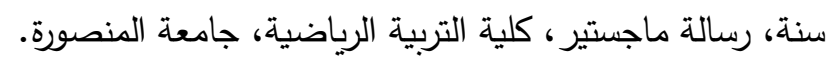

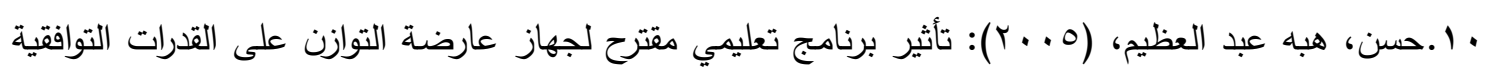

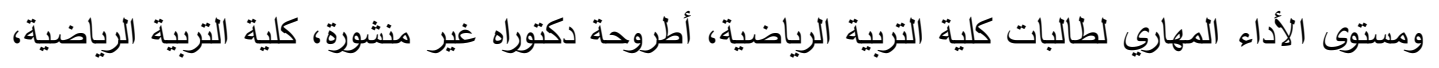

$$
\text { جامعة أسيوط. }
$$

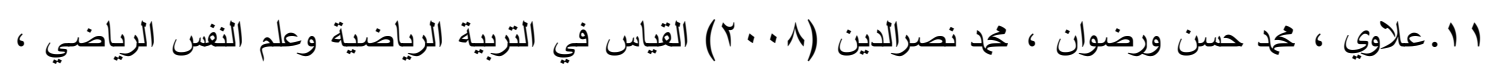
دار الفكر العربي للطباعة والنشر ، القاهرة. 


\section{ملحق رقم (1)}

أسماء السادة المتخصصين الذين عرضت عليهم استمارة اختبارات القدرات التوافقية

\begin{tabular}{|c|c|c|c|}
\hline مكان العمل & التخصص & اللقب العلمي والاسم & ت \\
\hline كلية التربية البدنية وعلوم الرياضة / جامعة الموصل & تعلم حركي /ساحة وميدان & | أ.د. جاسم تحمد نايف الرومي & 1 \\
\hline كلية التربية البدنية وعلوم الرياضة / جامعة الموصل & قياس وتقويم / كرة سلة & | أ.د. هاثم احمد سليمان & $r$ \\
\hline كلية التربية البذنية وعلوم الرياضة / جامعة تكريت & تعلم حركي / كرة قدم & أ.د. تحمل خضر اسمر & $r$ \\
\hline كلية التربية البدنية وعلوم الرياضة / جامعة الموصل & قياس وتقويم / كرة القدم & | أ.د. مكي محمود حسين & $\varepsilon$ \\
\hline كلية التربية البذنية وعلوم الرياضة / جامعة تكريت & قياس وتقويم / كرة القدم & | أ.د.عبدالمنعم الجنابي & $\bullet$ \\
\hline كلية التربية البدنية وعلوم الرياضة / جامعة الموصل & تعلم حركي/ كرة القدم & | أ.د. نوفل فاضل رشيد & 7 \\
\hline كلية التربية البدنية وعلوم الرياضة / جامعة الموصل & علم تدريب / كرة قدم & | أ.م.د. معن عبدالكريم & $\mathrm{v}$ \\
\hline كلية التربية البدنية وعلوم الرياضة / جامعة الموصل & قياس وتقويم / كرة القدم & | أ.م.د. عمر سمير ذنون & $\Lambda$ \\
\hline كلية التربية البدنية وعلوم الرياضة / جامعة الموصل & قياس وتقويم / جمناستك & | أ.م.د. علي حسين طبيل & 9 \\
\hline كلية التربية البلنية وعلوم الرياضة / جامعة الموصل & علم تدريب / كرة القلم & | أ.م.د. محمود حمدون & $1 \cdot$ \\
\hline كلية التربية البلنية وعلوم الرياضة / جامعة الموصل & تعلم حركي / مصارعة & | م.د. زياد طارق حامد & 11 \\
\hline كلية التربية البدنية وعلوم الرياضة / جامعة الموصل & علم تدريب / كرة القدم & م.د. محمد شاكر & Ir \\
\hline
\end{tabular}

